\title{
FINE AND HYPERFINE STRUCTURE IN THE SPECTRUM OF SECULAR VARIATIONS OF ATMOSPHERIC ${ }^{14} \mathrm{C}$
}

\author{
PAUL E DAMON, SONGLIN CHENG \\ Department of Geosciences \\ and \\ TIMOTHY W LINICK
}

Department of Physics, University of Arizona, Tucson, Arizona 85721

\begin{abstract}
The coarse structure of the ${ }^{14} \mathrm{C}$ spectrum consists of a secular trend curve that may be closely fit by a sinusoidal curve with period ca $11,000 \mathrm{yr}$ and half amplitude $\pm 51 \%$. This long-term trend is the result of changes in the earth's geomagnetic dipole moment. Consequently, it modulates solar components of the ${ }^{14} \mathrm{C}$ spectrum but does not appear to modulate a component of the spectrum of ca $2300-y r$ period. The ca $2300-y r$ period is of uncertain origin but may be due to changes in climate because it also appears in the $\delta^{18} \mathrm{O}$ spectrum of ice cores. This component strongly modulates the well-known ca $200-y r$ period of the spectrum's fine structure. The hyperfine structure consists of two components that fluctuate with the 11-yr solar cycle. One component results from solar-wind modulation of the galactic cosmic rays and has a half-amplitude of ca $\pm 1.5 \%$. The other component is the result of ${ }^{14} \mathrm{C}$ production by solar cosmic rays that arrive more randomly but rise and fall with the 11-yr cycle and appear to dominate the fluctuation of the galactic cosmic-ray-produced component by a factor of two.
\end{abstract}

\section{INTRODUCTION}

By the time of the 13th International Radiocarbon Conference in Trondheim, Norway in June 1985, five laboratories were systematically producing accurate ${ }^{14} \mathrm{C}$ calibration data at a precision of \pm 2 to $\pm 3 \%$ from dendrochronologically dated tree rings back to the ninth millennium BC. These results were summarized in the Calibration Issue of RADIOCARBON (Stuiver $\& \mathrm{Kra}, 1986)$. Figure 1 shows the high precision data of Stuiver and Pearson (1986), Pearson and Stuiver (1986) and Pearson et al (1986) for bi-decadal intervals plotted with the summary presented in Merrill and McElhinny (1983) of past variations in the geomagnetic dipole field intensity.

As is well known, ${ }^{14} \mathrm{C}$ is produced by the secondary neutrons released by cosmic-ray spallation in the atmosphere by a ${ }^{14} \mathrm{~N}(\mathrm{n}, \mathrm{p}){ }^{14} \mathrm{C}$ reaction and its production rate is proportional to $M(t)^{-\alpha}$ where $M(t)$ is the geomagnetic dipole moment and $\alpha=0.52$ (Elsasser, Ney \& Winckler, 1956). The rate of production is high when the field strength is low and vice versa. Figure 1 shows that atmospheric ${ }^{14} \mathrm{C}$ concentrations are in qualitative agreement with this relationship and, in fact, the $\Delta^{14} \mathrm{C}$ trend curve can be successfully modeled with permissible initial reservoir parameters as due entirely to production rate change resulting from changes in the earth's geomagnetic field based on the paleomagnetic data (eg, Sternberg \& Damon, 1979). There remains the possibility that part of this secular variation of atmospheric ${ }^{14} \mathrm{C}$ is the result of changes in the reservoir parameters but, if so, it is a secondorder effect (Stuiver, Pearson \& Braziunas, 1986). It seems that Le Chatelier's principle tends to operate in complex as well as simple systems and climatically induced shifts in reservoir parameters during the Holocene are compensated by concomitant shifts in other parameters in such a way as to minimize the effect of the disturbance (eg, Damon, 1970).

The trend of $\Delta{ }^{14} \mathrm{C}$, excluding short-term fluctuations, can be approxi-

Deceased 


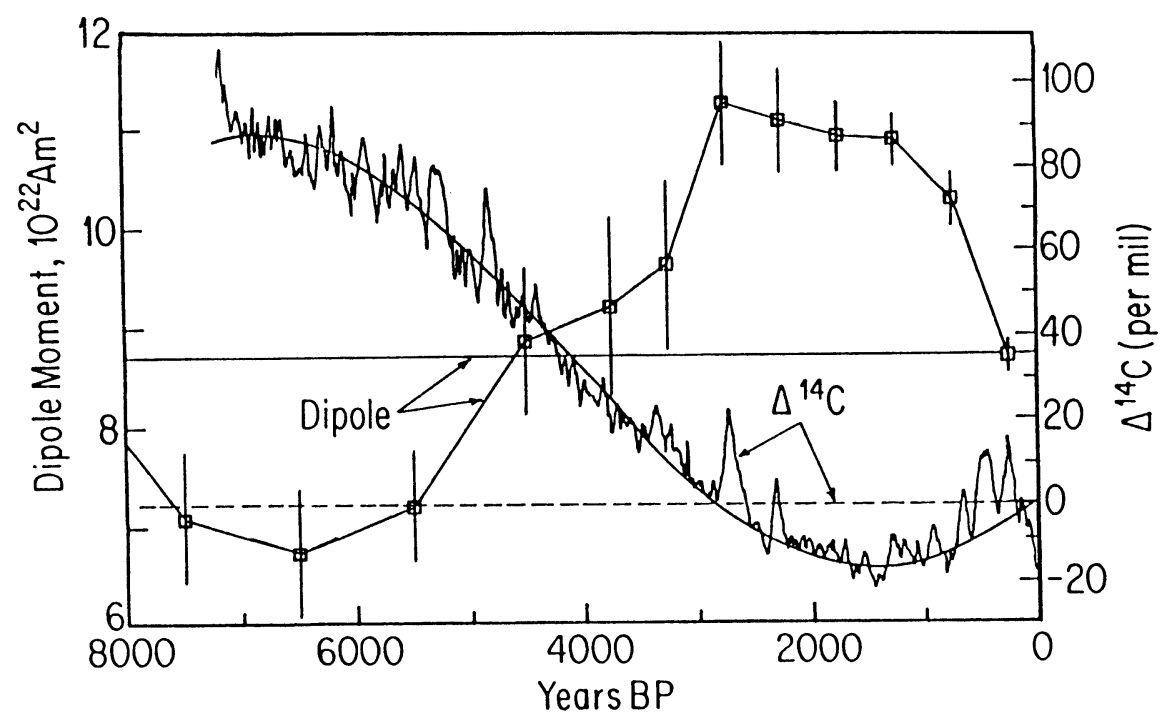

Fig 1. High-precision data $( \pm 2 \%$; Stuiver \& Pearson, 1986; Pearson \& Stuiver, 1986; Pearson et al, 1986) for dendrochronologically dated, 20 -yr tree-ring intervals. The equation of the curve is:

$$
\Delta^{14} \mathrm{C}(\%)=35+51 \sin \left(5.826 \times 10^{-4} \mathrm{t}-2.401\right)
$$

corresponding to a period of $10,780 \mathrm{yr}$ with a phase lag of 2.401 radians or $137.6^{\circ}$. The ${ }^{14} \mathrm{C}$ data are compared with a summary of archaeometric determinations of the strength of the earth's dipole moment. Data are from Merrill and McElhinny (1983). The vertical error bars are for $\pm 95 \%$ error limits. The authors calibrated the ${ }^{14} \mathrm{C}$ time scale using an older smoothed calibration scheme to $6500 \mathrm{BP}$ (Clark, 1975) and a linear interpolation to an assumed ${ }^{14} \mathrm{C}$ true age convergence at $10,000{ }^{14} \mathrm{C}$ yr. This affects primarily the last point which should be shifted from 7500 to $7800 \mathrm{BP}$. Note that the inverse relation between $\Delta^{14} \mathrm{C}$ and dipole moment, lag time of the $\Delta^{14} \mathrm{C}$ and relative suppression of the de Vries Effect or Suess wiggles when the field strength is high agree with modulation of ${ }^{14} \mathrm{C}$ production by the earth's dipole moment.

mated by a sinusoidal curve with a period of ca 11,000 years back to $6500 \mathrm{BC}$ (Bruns et al, 1983; Damon \& Linick, 1986) but may deviate from a sinusoidal curve prior to that time (Kromer et al, 1986). Figure 1 shows that the trend curve is modulated by shorter-term fluctuations that are quasi-periodic with a ca 200 -yr period (Suess, 1980) and correlate with solar minima. There is general agreement that the inverse relationship between ${ }^{14} \mathrm{C}$ production and solar activity as measured by sunspots during the 11-yr solar cycle also holds for the various solar minima such as the Maunder, Spoerer and Wolf minima (Eddy, 1976a,b; Stuiver \& Quay, 1980) and it has been suggested that climatic effects are not the main cause of short-term variation of either ${ }^{14} \mathrm{C}$ or ${ }^{10} \mathrm{Be}$ during the Holocene (Stuiver, Pearson \& Braziunas, 1986; Beer et al, 1988). However, other workers consider the role of climate as a forcing function is significant (Lal, Laffoon \& Erickson, 1988; Damon \& Sonett, 1989). We will refer to these solar-activity-induced, short-term secular variations of atmospheric ${ }^{14} \mathrm{C}$ as the "fine structure". 


\section{MODULATION OF SOLAR-INDUCED FINE STRUCTURE BY CHANGE IN THE EARTH'S DIPOLE MOMENT}

If we exclude for the moment the larger medium-term fluctations that occurred during "Hallstattzeit" (700-200 BC)(Schmidt \& Gruhle, 1988) and during the Little Ice Age (AD 1400-1850)(Lamb, 1965), Figure 1 shows that, when the geomagnetic dipole field was higher than at present after $4500 \mathrm{BP}$, the fine structure is suppressed in amplitude and the average fine-structure amplitude is noticeably greater before $4500 \mathrm{BP}$ when the dipole field was less than at present. According to Lingenfelter and Ramaty (1970, Fig 3), the global average production rate from solar maximum to solar minimum would vary by $\Delta \mathrm{Q}=0.38^{14} \mathrm{C} \mathrm{cm}^{-2} \mathrm{sec}^{-1}$ for the maximum of the dipole moment at ca $11 \times 10^{22} \mathrm{Am}^{2}$ to $\Delta \mathrm{Q}=0.60{ }^{14} \mathrm{C} \mathrm{cm}^{-2} \mathrm{sec}^{-1}$ for the minimum of the dipole moment at ca $7 \times 10^{22} \mathrm{Am}^{2}$. Lal (1988) predicts a greater variation in ${ }^{14} \mathrm{C}$ production from solar maximum to solar minimum but approximately the same relative suppression of production at higher geomagnetic field strengths. This is in qualitative agreement with the variation in the amplitude of the fine structure from dipole moment maximum to minimum in Figure 1. Thus, both the major trend of secular, atmospheric ${ }^{14} \mathrm{C}$ fluctuation and the variation of the amplitude of the solar-induced fine structure are compatible with the paleomagnetic record of dipole field intensity. However, the unusually large "Suess wiggles" during Hallstattzeit and the Little Ice Age require further explanation

In order to observe the fine structure more clearly, we remove the sinusoidal trend curve to obtain Figure 2 and fit the data with the ARSTAN cubic spline routine (Cook \& Holmes, 1985) with stiffness 5. The low stiffness spline clearly follows the ${ }^{14} \mathrm{C}$ increases during the Dalton, Maunder, Spoerer and Wolf solar minima. Peaks of approximately the same size as the Maunder and Spoerer minima that occur at 250 and $450 \mathrm{BP}$ also occur ca 2700,4870 and $7150 \mathrm{BP}$. Thus, singlet or doublet peaks of Maunder minimum amplitude occur every 2100-2400 yr. Next, we used the ARSTAN cubic spline program as a low pass filter gradually increasing the stiffness. Shown in Figure 3 is the fit at stiffness 20 and Figure 4 is the stiffness 80 , which produces a quasi-sinusoidal curve with a period of ca $2300 \mathrm{yr}$. Houtermans (1971) first observed a similar periodicity of $2250 \pm 50 \mathrm{yr}$ by Fourier spectral analysis of the La Jolla data set. His analysis has been confirmed by a number of authors with values ranging from a low estimate of $2080 \mathrm{yr}$ (Sonett, 1984) and a high estimate by Suess (1980) of $2400 \mathrm{yr}$. There seems to little doubt that the quasi-sinusoidal variation of $2100-2400 \mathrm{yr}$ is present in the ${ }^{14} \mathrm{C}$ record in tree rings. A similar periodicity is present in the Greenland ice core oxygen isotope record, ca $2000 \mathrm{yr}$, back to 45,000 yr (Dansgaard et al, 1971). Lund and Banerjee (1985) find evidence for a fundamental wave length of $2400 \mathrm{yr}$ with harmonics at 1200,800 and $600 \mathrm{yr}$ for secular variation of the directional components of the paleomagnetic field in late Quaternary lake cores. They observe that "the fundamental wave length of $2400 \mathrm{yr}$ is very noteworthy because that is the estimated time for the non-dipole field to rotate $360^{\circ}$ due to westward drift" (Lund \& Banerjee, 1985, p 821). However, because the intensity of non-dipole components is inversely proportional to $\mathrm{r}^{\mathrm{n}}$ where 


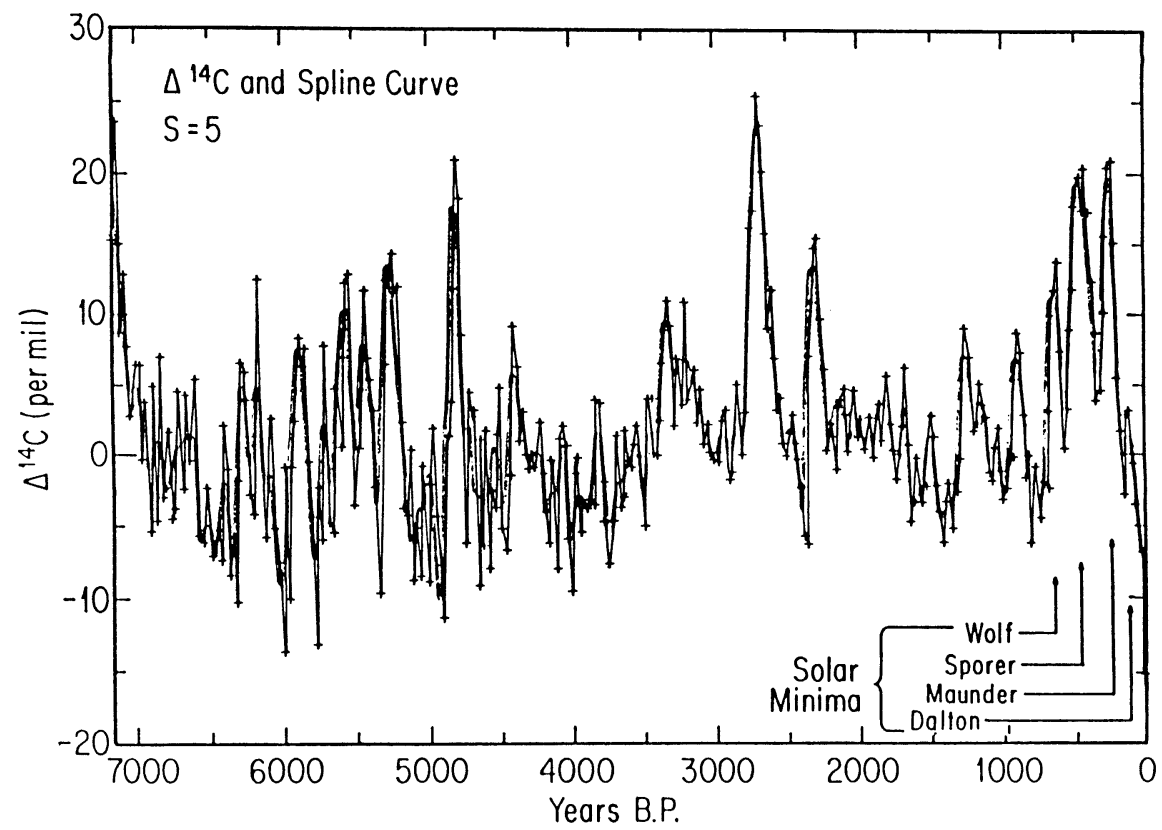

Fig 2. Solar-induced de Vries Effect (Suess wiggles) after subtraction of the 10,780-yr sinusoid. Unusually large wiggles occur every $2100-2400$ yr but, with this exception, the wiggles are relatively suppressed when the magnetic field was higher than at present to $4000 \mathrm{yr}$ BP as expected from theoretical considerations. Stiffness $(\mathrm{S})$ of cubic spline $=5$.

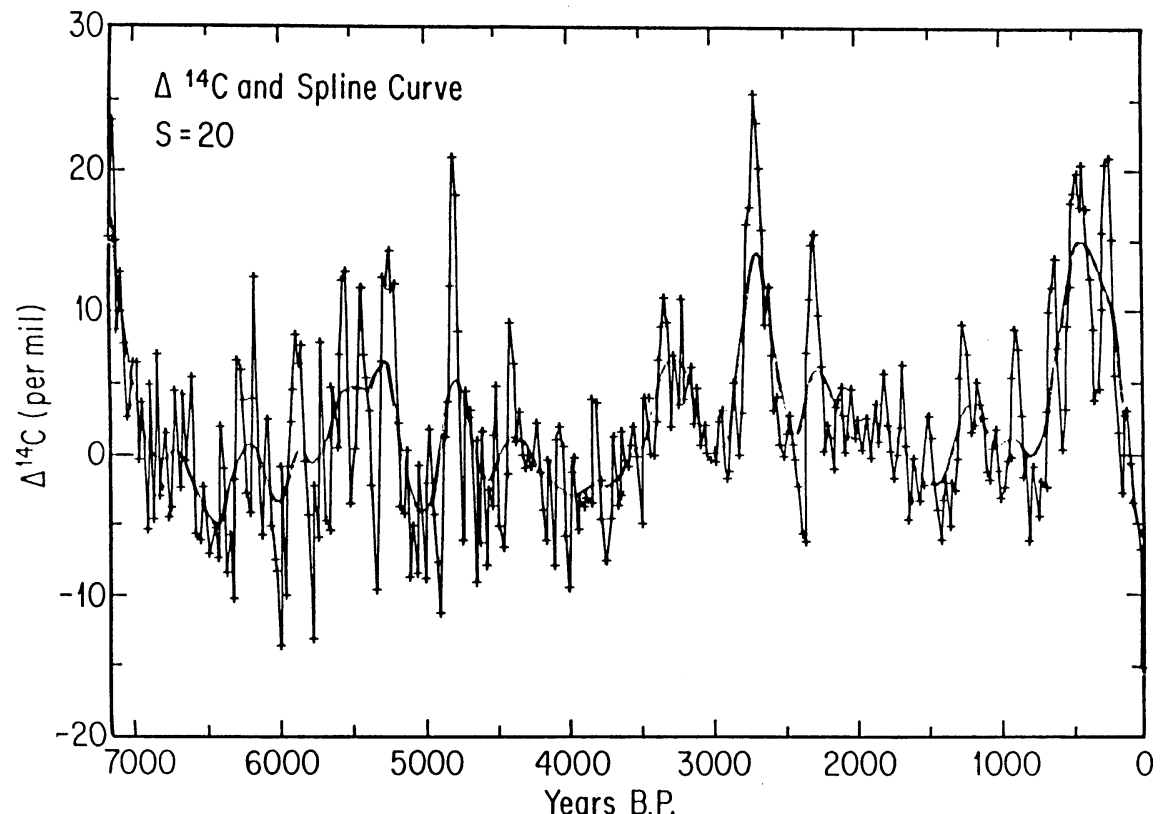

Fig 3. As the stiffness of the spline is increased $(S=20)$, the resultant curve takes on the appearance of a quasi-sinusoid with harmonics. 


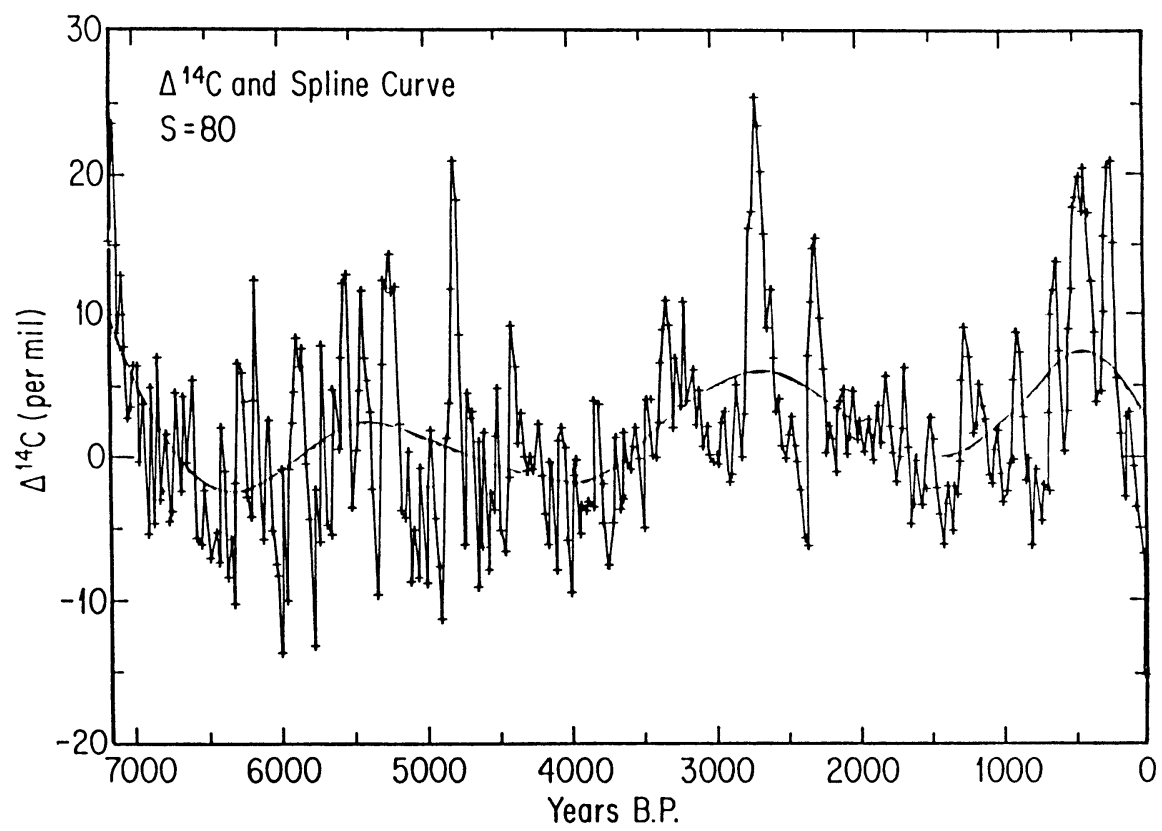

Fig 4. When the stiffness of the spline is further increased to $S=80$, the cubic spline curve takes the form of a quasi-sinusoid with wave length between 2100 and $2400 \mathrm{yr}$. Note that the solar-induced wiggles rise and fall with both the ca $2400-\mathrm{yr}$ and $10,780 \mathrm{yr}$ cycles. This is an expected result of modulation by components of the earth's dipole moment.

$\mathrm{n}>3$, the non-dipole field would have little affect on galactic cosmic rays reaching the earth's atmosphere to produce ${ }^{14} \mathrm{C}$.

At stiffness 20 (Fig 3), the fundamental quasi-sinusoidal wave length of $2100-2400 \mathrm{yr}$ is already visible along with higher frequency components of the fine structure. Figure 5 presents the high-frequency components of the solar-induced fine structure after removal of the ca 2300 -yr quasi-sinusoid. By comparing Figures 4 and 5, we see that the fine structure variability is highest near the maxima of the 2300 -yr cycle and lowest near the minima. In fact, the quasi-sinusoidal variation is actually following the rising and falling of the amplitude of the fine structure. Also, the overall fine-structure amplitude is highest prior to $5000 \mathrm{BP}$, when the paleomagnetic estimate of the dipole field strength was much lower than at present, relatively suppressed after 5000-1250 BP, when the dipole field strength appears to have been higher than at present, and increases again when the paleomagnetic data indicates that the dipole field strength was rapidly decreasing. These relationships agree with expectation if the solar-induced fine-structure amplitude had been modulated by both 11,000 - and 2300 -yr quasi-sinusoidal components of the earth's dipole field. Damon and Linick (1986, Fig 2) modeled this effect to obtain a curve very similar to the $\Delta^{14} \mathrm{C}$ secular variation curve shown in Figure 1.

Summarizing, the non-dipole field decreases at $1 / r_{n}$, where $n>3$ and, therefore, is too weak to modulate galactic cosmic rays at relevant distances 


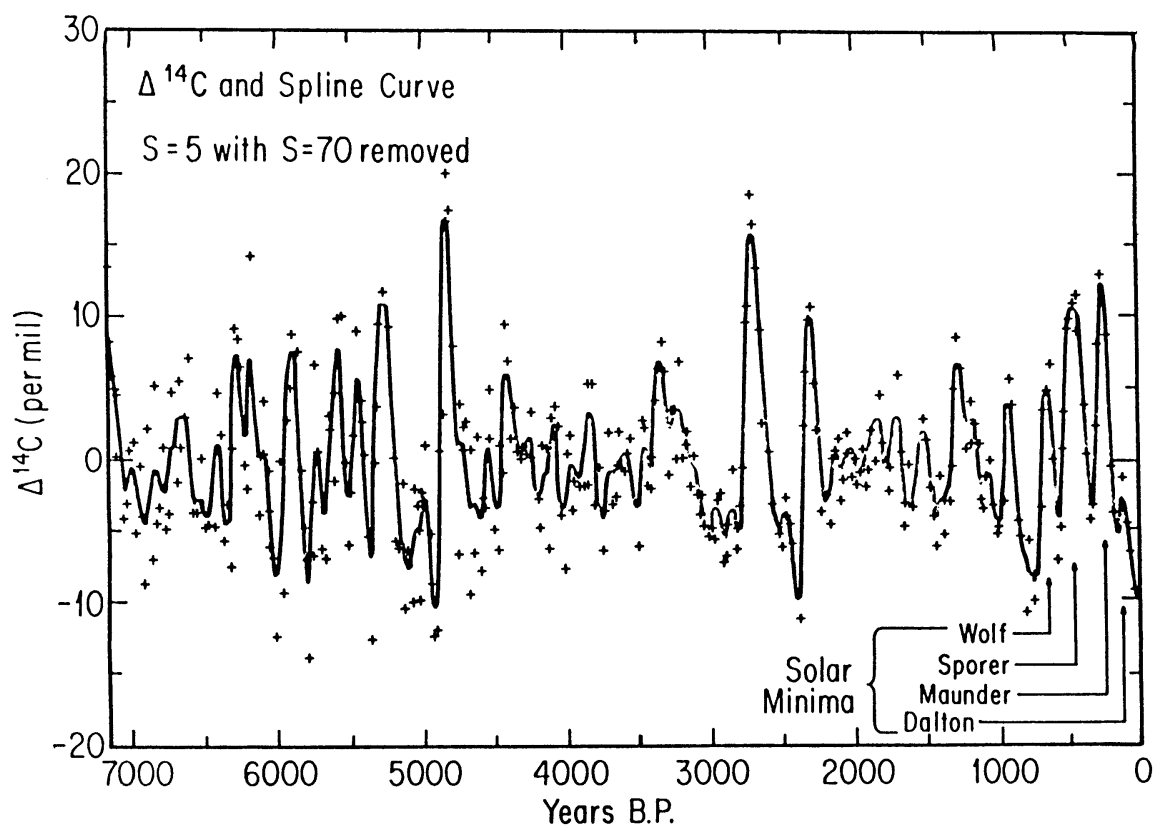

Fig 5. After removal of the ca 2400 -yr cycle, the modulation by components of the earth's dipole moment becomes even more apparent with little or no effect of possible harmonics ot the ca 2400 -yr cycle.

from the earth. As yet, we do not know the cause of the ca 2300 -yr oscillation in ${ }^{14} \mathrm{C}$ production.

Since the ca 2300 -yr variation is also present in the oxygen isotope record of the Greenland ice cap as reported by Dansgaard et al (1971), an interesting question is raised on a relationship between the earth's nondipole magnetic field and climate assuming that this correlation is not merely an accidental coincidence.

\section{HYPERFINE SECULAR VARIATIONS OF ${ }^{14} \mathrm{C}$ : SUNSPOT CYCLE AND SOLAR FLARES}

In August 1969 at the Twelfth Nobel Symposium on Radiocarbon Variations and Absolute Chronology, Lingenfelter and Ramaty (1970) presented calculations of the ${ }^{14} \mathrm{C}$ production rate for solar cycle 19 . There are two components of ${ }^{14} \mathrm{C}$ production, ie, production by galactic cosmic rays and solar flares. Galactic cosmic rays produce secondary neutrons that form ${ }^{14} \mathrm{C}$ throughout the earth's atmosphere whereas solar flare production of neutrons and consequent ${ }^{14} \mathrm{C}$ production is concentrated in the stratosphere. Galactic cosmic rays produce ca $44 \%$ of ${ }^{14} \mathrm{C}$ in the troposphere and the remaining $56 \%$ in the stratosphere (Lal \& Peters, 1967). Lingenfelter and Ramaty's (1970) calculations for solar cycle 19 indicated that the production rate due to galactic cosmic rays varied from $2.42{ }^{14} \mathrm{C} \mathrm{cm}^{-2} \mathrm{sec}^{-1}$ at solar minimum (1953-1954) to $1.93{ }^{14} \mathrm{C} \mathrm{cm}^{-2} \mathrm{sec}^{-1}$ at solar maximum (1957-1958). They estimated the solar flare production during that cycle to be between $6 \%$ and $14 \%$ of the solar-cycle-averaged cosmic-ray production rate with ca 
$70 \%$ of the production resulting from the single large flare of February 23, 1956. They pointed out that the negative correlation of ${ }^{14} \mathrm{C}$ production with solar activity would be completely obscured by the enhanced production from solar flares during that cycle. Castagnoli and Lal (1980, p 153) suggested that "it should be possible to see such solar flare effects in careful ring by ring (tree rings) analyses". The calculations of these researchers led us to make a study of single rings from the Radio Ridge tree. We used high-precision proportional counting and determined the carbon isotopes in cellulose from annual rings (Linick et al, 1986).

The Radio Ridge tree (Douglas fir) grew in the Santa Catalina Mountains of southern Arizona before it was cut during the winter of 1969-1970 $\left(32^{\circ} 26^{\prime} \mathrm{N}, 110^{\circ} 47^{\prime} \mathrm{W}\right.$; elev $\left.2740 \mathrm{~m}\right)$. The transition from sapwood to heartwood occurred prior to the 1940 ring but the extraction of cellulose avoids any error due to radial translocation of carbon (Cain, 1976; Long et al, 1979). We chose to study the period from 1930-1955 because the high-precision data of Stuiver and Quay (1981) for cellulose extracted from single tree rings from their tree $\mathrm{C}$ show pronounced maxima and minima approximately a decade apart for this period. Tree $\mathrm{C}$ is a Douglas fir that grew on the Olympic Peninsula. Our results for the Radio Ridge tree are presented in Table 1 and plotted along with the results from tree $\mathrm{C}$ in Figure 6 . The counting precision for both sets of data averages ca $1.6 \%$.

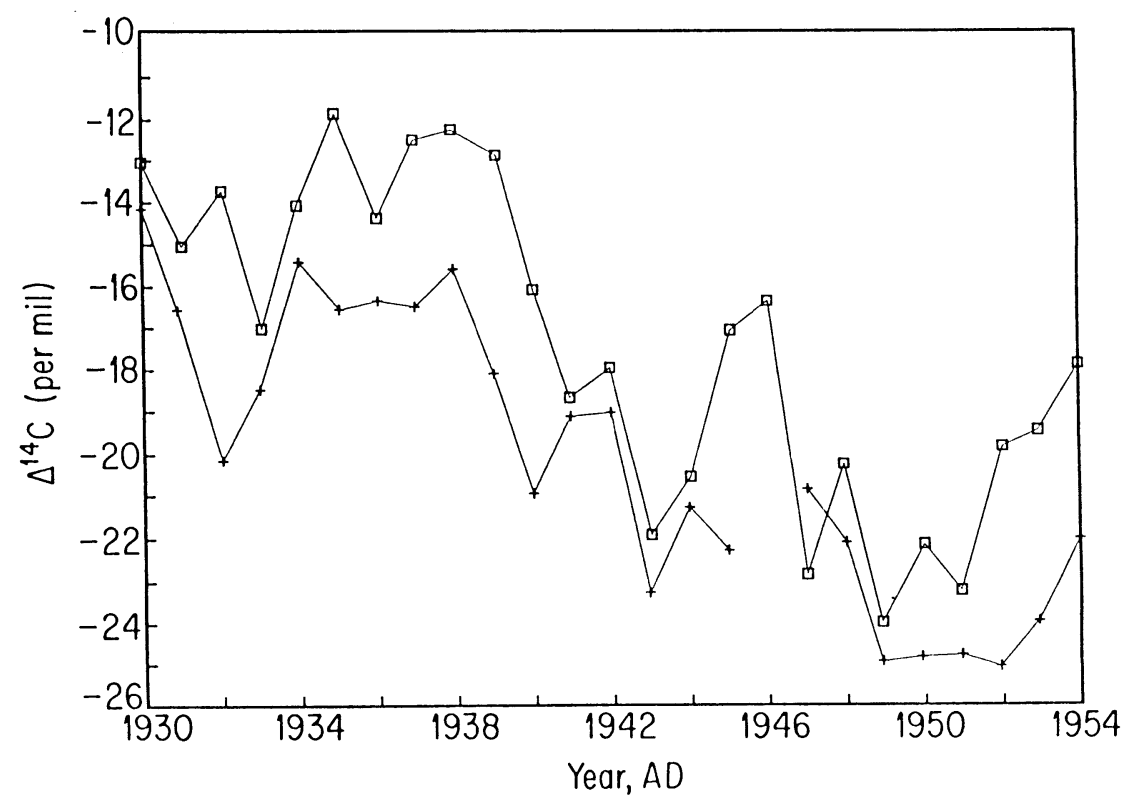

Fig 6. Arizona data ( $\square$ ) for Radio Ridge annual tree rings from the Santa Catalina Mts compared with the data of Stuiver and Quay (1981) for annual rings of a tree that grew on the Olympic Peninsula (+). The curves are displaced but each curve shows all of the significant features contained within the other. Note that the Olympic Peninsula tree's $\Delta^{14} \mathrm{C}$ lags that of the Radio Ridge tree during the increase due to nuclear weapons after 1951 . 
TABLE 1

Carbon isotope analyses for Radio Ridge single-year tree ring samples

\begin{tabular}{cccc}
\hline Lab no. & Year AD & $\delta^{13} \mathrm{C}(\%)$ & $\Delta^{14} \mathrm{C}(\%)$ \\
\hline $\mathrm{A}-4498$ & 1930 & -23.39 & $-13.0 \pm 1.4$ \\
-4499 & 1931 & -23.08 & $-15.0 \pm 1.5$ \\
-4500 & 1932 & -22.97 & $-13.7 \pm 1.3$ \\
-4496 & 1933 & $(-23.00)^{*}$ & $-17.0 \pm 1.7$ \\
-4497 & 1934 & $-23.00)^{*}$ & $-14.1 \pm 1.5$ \\
-4240 & 1935 & -22.71 & $-11.9 \pm 1.6$ \\
-4241 & 1936 & -21.62 & $-14.4 \pm 1.8$ \\
-4245 & 1937 & -21.07 & $-12.5 \pm 1.7$ \\
-4271 & 1938 & -22.02 & $-12.3 \pm 1.5$ \\
-4272 & 1939 & -21.94 & $-12.9 \pm 1.5$ \\
-4280 & 1940 & -21.86 & $-16.1 \pm 1.3$ \\
-4281 & 1941 & -22.30 & $-18.7 \pm 1.5$ \\
-4282 & 1942 & -20.95 & $-18.0 \pm 1.5$ \\
-4283 & 1943 & -21.14 & $-21.9 \pm 1.6$ \\
-4284 & 1944 & -21.65 & $-20.6 \pm 1.2$ \\
-4285 & 1945 & -22.11 & $-17.1 \pm 1.3$ \\
-4294 & 1946 & -21.57 & $-16.4 \pm 1.6$ \\
-4295 & 1947 & -21.05 & $-22.8 \pm 1.7$ \\
-4296 & 1948 & -21.27 & $-20.3 \pm 1.8$ \\
-4297 & 1949 & -21.58 & $-24.0 \pm 1.8$ \\
-4298 & 1950 & -21.37 & $-22.1 \pm 1.4$ \\
-4299 & 1951 & -21.13 & $-23.2 \pm 1.5$ \\
-4300 & 1952 & -21.18 & $-19.9 \pm 1.5$ \\
-4301 & 1953 & -21.11 & $-19.5 \pm 1.5$ \\
-4302 & 1954 & -21.54 & $-17.9 \pm 1.6$ \\
-4303 & 1955 & -21.58 & $+5.1 \pm 1.7$ \\
\hline & 139 & &
\end{tabular}

${ }^{*} \delta^{13} \mathrm{C}$ values in parentheses were not measured, but estimated from values measured for tree rings of adjacent years.

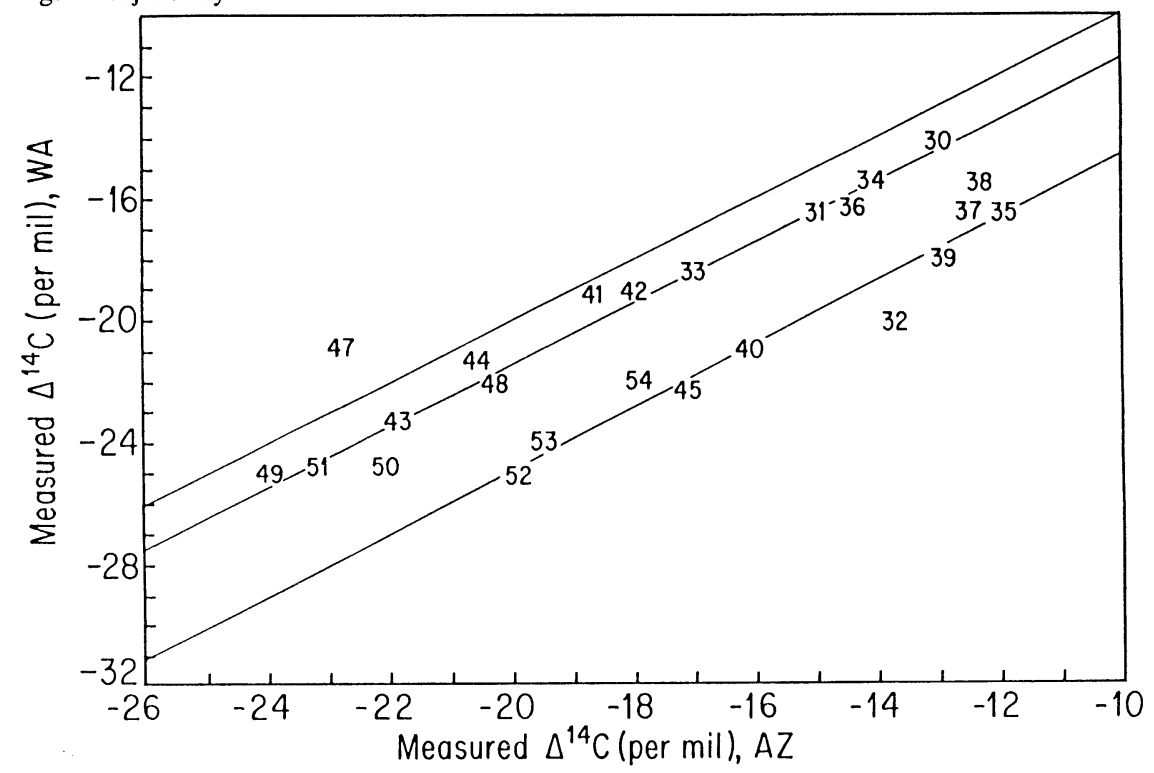

Fig 7. A correlation curve for the two sets of data show two lines parallel to the perfect agreement. The correlation coefficients for the two lines, excluding the data for 1947 (47), are surprisingly high (0.988 and 0.959 ). If we assume that the upper line is slightly displaced due to a calibration difference, the other Olympic Peninsula tree rings are still displaced by $3 \%$ lower than the Radio Ridge tree rings. Such a displacement could be produced by a mixing of $3 \%$ of $10 \%$ depleted $\mathrm{CO}_{2}$ from the prevailing air mass. 
Figure 6 shows that both sets of data present the expected Suess-effect decline in ${ }^{14} \mathrm{C}$ activity, in parts per mil $\left(\Delta^{14} \mathrm{C}\right)$ relative to mid-19th century wood, resulting primarily from the combustion of fossil fuels. The pronounced maxima and minima are present in both data sets, which also show the pronounced increase in ${ }^{14} \mathrm{C}$ activity after 1951 that resulted from nuclear weapons tests. By $1955,{ }^{14} \mathrm{C}$ activity of the Radio Ridge ring for that year had risen to $+5.1 \pm 1.7 \%$ o (Table 1), placing it far off the graph in Figure 6 . Also, except for 1947, the Arizona data always indicate a, more or less, higher ${ }^{14} \mathrm{C}$ activity, averaging ca $2.5 \%$. Just before this study, we had compared seven decadal samples of Bristlecone pine from the White Mountains of California with Stuiver and Quay's (1980) decadal data for tree rings from Douglas fir that grew in Oregon and found no significant difference (Linick et al, 1986). This difference of $2.5 \%$ would not be difficult to rationalize as the result, eg, of a mixture of only $2.5 \%$ of $10 \%{ }^{14} \mathrm{C}$-depleted $\mathrm{CO}_{2}$ derived from the marine upwelling with undepleted $\mathrm{CO}_{2}$ in the prevailing air masses of the Olympic Peninsula. Upon plotting a correlation diagram of the Washington and Arizona data, we were surprised to find that the data lie with high correlation around two completely separate lines closely parallel to the line of perfect agreement (Fig 7). Excluding the anomalous 1947 data, the correlation coefficient for the upper line is 0.988 and 0.959 for the lower line. If we assume that the displacement of the upper line is the result of calibration difference, correcting by that amount would still leave samples on the lower line depleted by ca $3 \%$ in ${ }^{14} \mathrm{C}$. If the discrepancy is due to north Pacific Ocean upwelling, this would require, eg, $3 \%$ of $10 \%$ depleted air in the resulting air mass reaching the Olympic Peninsula. This does not seem to be an inordinate amount but would require episodic mixing. As an example of a possible air mass mixing effect, consider the eight years from 19471954. The first five of these years lie near the line closest to perfect agreement. During the remaining three years, 1952-1954, the specific ${ }^{14} \mathrm{C}$ activity of the Arizona tree increases at a greater rate than the Olympic Peninsula tree. This might be expected from the closer proximity of the Arizona site to the Nevada testing area considering prevailing movement of air masses in western North America. In this case, Arizona air need only be enriched by ca 3\% relative to air prevailing over the Olympic Peninsula. More detailed discussion of meteorological factors is beyond the scope of this paper.

The next step in analysis was to normalize the data to correct for the bias between the two sets of data by multiplying each Washington datum point by the slope appropriate to the line it falls closest to and adding the appropriate intercept. The slopes are so nearly unity (1.002 and 1.035) that the correction is almost equal to adding $1.4 \%$ to Washington data lying closest to the upper line and $4.2 \%$ to the data lying on the lower line. The data were then averaged to obtain the composite data set shown in Figure 8.

Comparing Figures 8 and 6, normalized composite data set reproduces all of the significant features shown by either data set separately. Because our purpose is to evaluate the effect of solar flares, we next removed the Suess effect and the 11-yr cycle of galactic cosmic-ray-related ${ }^{14} \mathrm{C}$ production. We approximated the Suess effect by a cubic spline (ARSTAN program) with stiffness (S) 35, which is the solid curve in Figure 8. The predicted 11-yr 


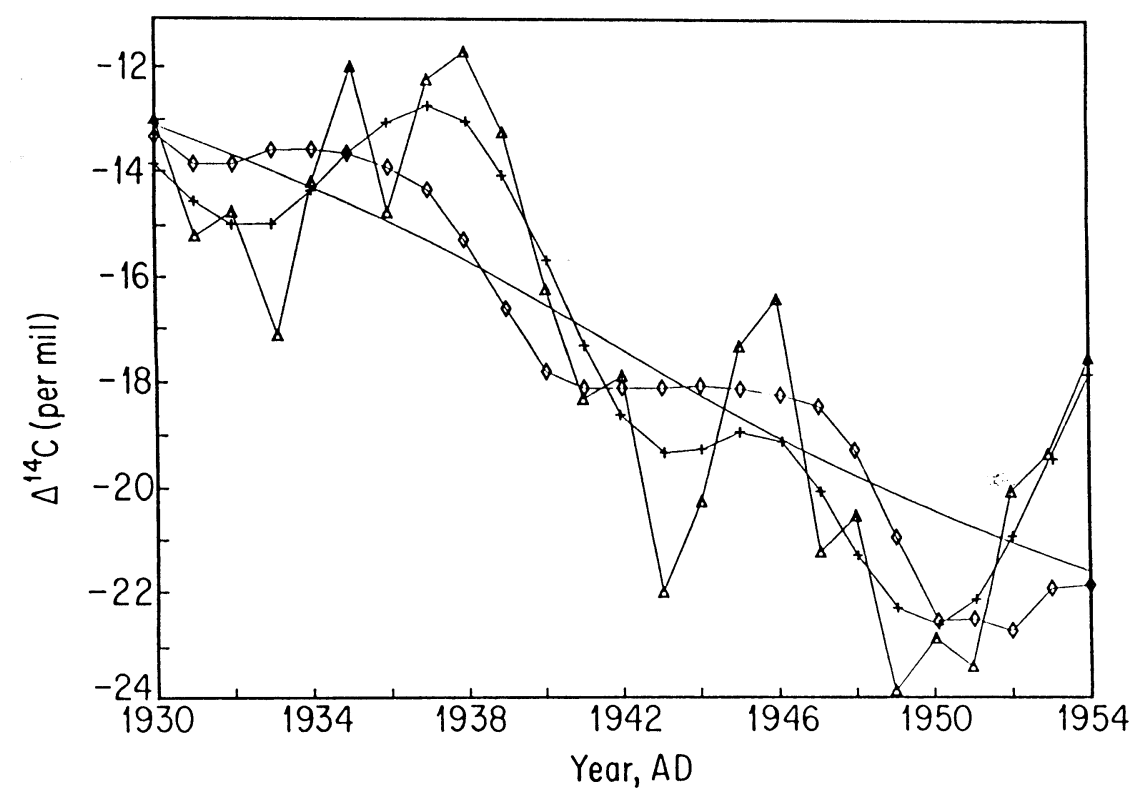

Fig 8 . The data are normalized and plotted $(\Delta)$. Two cubic splines are fit to the data. One follows the wiggles $(\mathrm{S}=8,+)$ and the other follows the trend $(\mathrm{S}=35,-)$. A third curve is obtained by a linear fit for the relationship between ${ }^{14} \mathrm{C}$ production and sunspots during the $11-\mathrm{yr}$ solar cycle (see text). The production rate is then modeled and plotted $(\diamond)$ using the box-diffusion model of Oeschger et al (1975). Note that the cubic spline $(\mathrm{S}=8)$ is distorted relative to the expected $11-\mathrm{yr}$ cycle.

cycle in ${ }^{14} \mathrm{C}$ was obtained by using a linear approximation relating Lingenfelter and Ramaty's (1970) production data to the Zurich sunspot numbers (S):

$$
\mathrm{Q}=2.434-0.00264 \mathrm{~S}^{14} \mathrm{C} \mathrm{sec}^{-1} \mathrm{~cm}_{\mathrm{e}}^{-2^{-6}}
$$

We then calculated the production rate for each year relative to the mid19th century production rate and fed this into the box-diffusion model of Oeschger et al (1975). Details of deriving the 11 -yr cycle of ${ }^{14} \mathrm{C}$ from the various published box models are given in Damon, Sternberg and Radnell (1983). Figure 8 shows the sum of the $11-\mathrm{yr}$ cycle in ${ }^{14} \mathrm{C}$ and the estimated Suess effect, which may be compared with the cubic spline with $S=8$. The cycle produced by the $S=8$ spline is short by a year and relatively distorted. We then subtracted the sum of the Suess effect and the predicted 11-yr cycle in ${ }^{14} \mathrm{C}$ to obtain the residual signal, which would be the part of the original secular fluctuation that cannot be explained by the Suess effect or the galactic component of cosmic rays. Presumably, this would be the solar cosmic-ray component primarily related to solar flares. The residual is shown in Figure 9. 


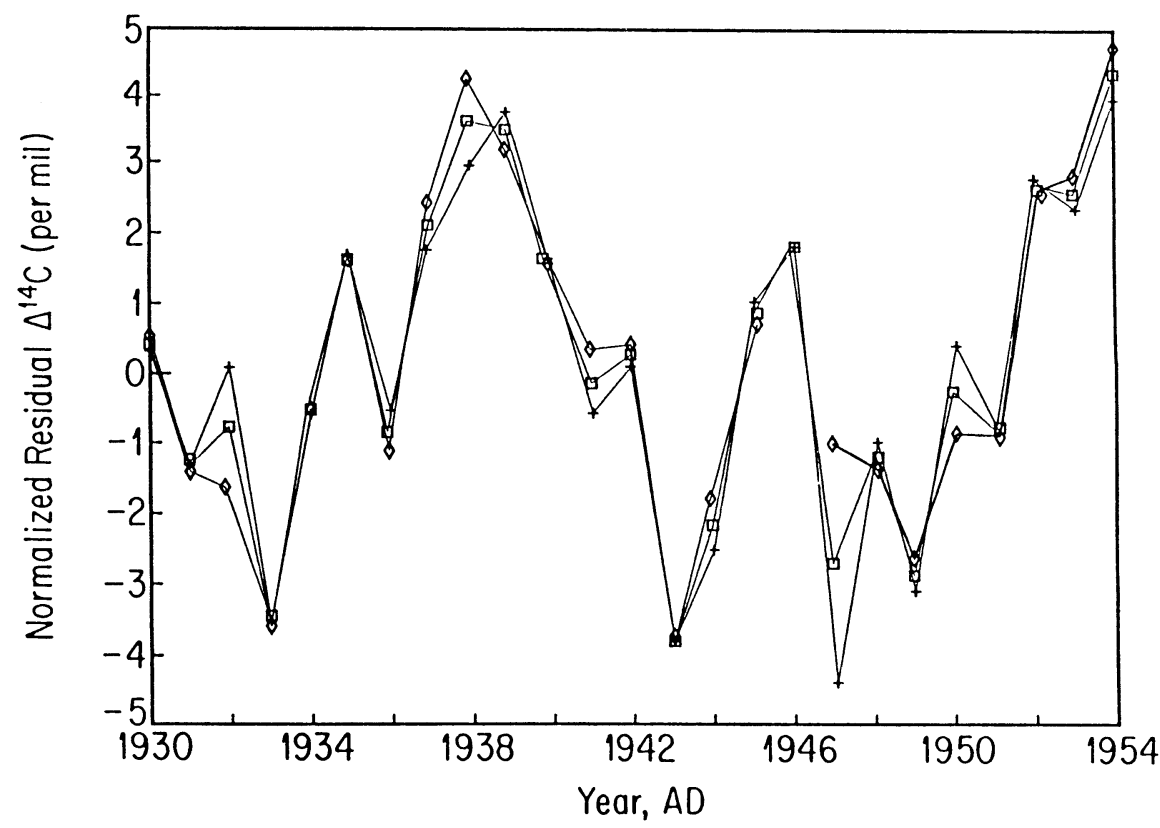

Fig 9. The sum of the trend curve approximating the Suess Effect which is dominantly due to combustion of fossil fuels and the predicted 11-yr cycle is subtracted from the normalized data points (Arizona $=+$, Washington $=\diamond$, average $=\square$ ) and plotted. The residual signal shows $\pm 3 \%$ fluctuation followed by an increase in the early 1950 s due to explosion of nuclear weapons.

Figure 9 shows that the residuals from both sets of normalized data are very similar. Also the fluctuation of the residual signal is twice the intensity of the predicted 11-yr cycle produced by solar modulation of galactic cosmic rays or $\pm 3.5 \%$ rather than $3.2 \%$ peak to peak. Figure 8 shows that the distortion of the 11-yr cycle produced by the cubic spline with $\mathrm{S}=8$ is caused by the tendency of the cubic spline to follow the larger residual signal. In Figure 10 , the residual signal is compared to $\mathrm{Aa}^{*}$ indices and the Wolf sunspot number. The $\mathrm{Aa}^{*}$ indices are derived from $\mathrm{Aa}$ indices that reflect the magnitude of short-term $(3 \mathrm{hr})$ random occurrences of magnetic activity obtained by using antipodal magnetic stations in England and Australia (Mayhaud, 1972). Index values above 60 are considered to be highly significant solar storms. The $\mathrm{Aa}^{*}$ indices above 60 are summed for each year for the plot in Figure 10.

Figure 10 shows that $\left(\mathrm{Aa}^{*}-60\right)$ and the ${ }^{14} \mathrm{C}$ residuals reach minimum values during the sunspot minima and reach maximum values during the falling part of the sunspot cycle (AD 1938-1941) or the rising part of the sunspot cycle (1946). Thus, there seems to be first-order evidence for a solar component to the residual ${ }^{14} \mathrm{C}$ signal. However, a closer look leads to questions such as why does the residual ${ }^{14} \mathrm{C}$ signal lead the $\left(\mathrm{Aa}^{*}-60\right)$ indices during the first part of the solar cycle and why is there little or no lag time between $\left(\mathrm{Aa}^{*}-60\right)$ maxima and residual ${ }^{14} \mathrm{C}$ maxima? These second-order discrepancies may lie, at least in part, in the assumptions and approximations that were made. For example, we have assumed a linear relationship between ${ }^{14} \mathrm{C}$ production and 


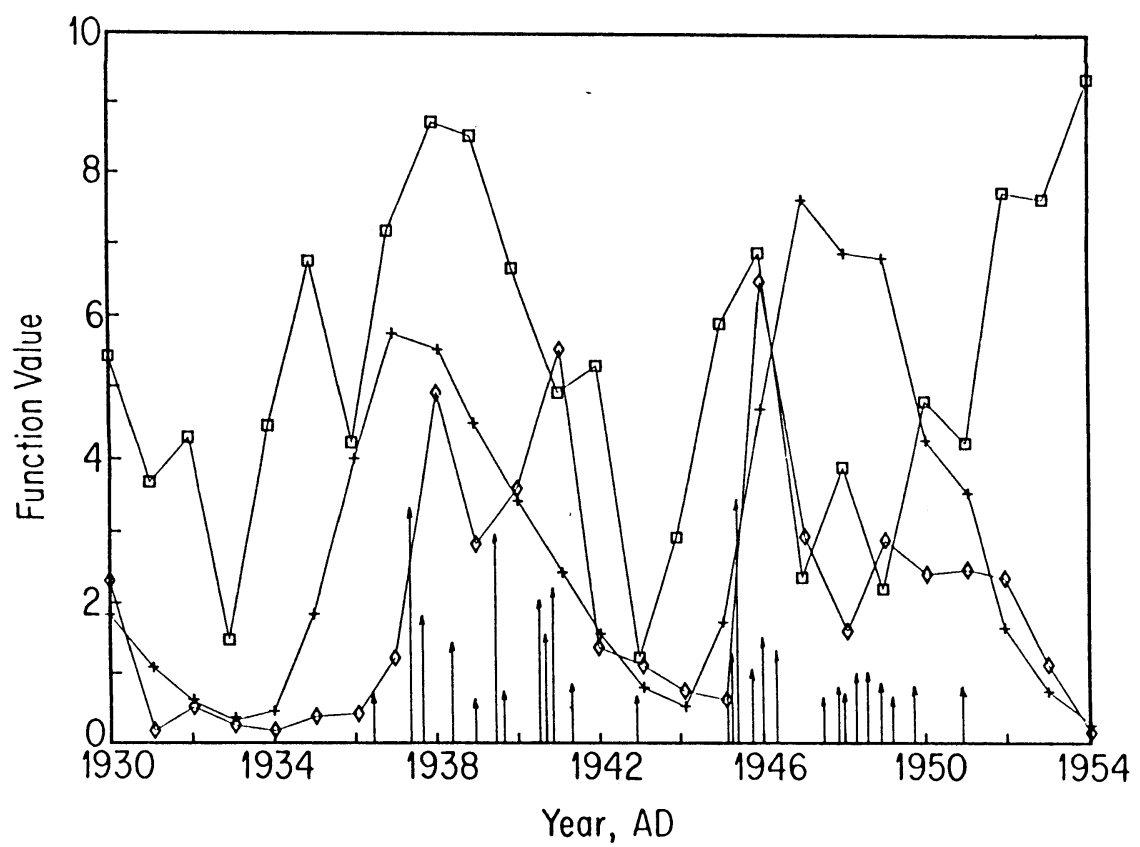

Fig 10. The average residual plus $5 \%$ o $(\square)$, sunspot numbers multiplied by $0.05(+)$ and the sum of all $\mathrm{Aa}^{*}$ indices exceeding $60\left[\left(\mathrm{Aa}^{*}-60\right) \times 0.005, \diamond\right]$ are plotted and joined by lines. The arrows are for the sum of monthly solar storms of magnitude $\mathrm{Aa}^{*} \geq 120$. Note that both residual ${ }^{14} \mathrm{C}$ and the $\mathrm{Aa}^{*}$ index are a minimum at solar minimum and maximize during the rising or falling part of the solar cycle. The residual ${ }^{14} \mathrm{C}$ approaches zero during solar minimum and rises ca $6 \%$ following solar minimum. If this rise is attributed to solar protons, the average ${ }^{14} \mathrm{C}$ content of the atmosphere is increased by $3 \%$ during the 17 th and 18 th solar cycle. Because the attenuation of the box-diffusion model as parameterized is 54 , solar protons produced an amount of ${ }^{14} \mathrm{C}$ equal to $16 \%$ of the ${ }^{14} \mathrm{C}$ produced by galactic cosmic rays. Second-order discrepancies are discussed in the text.

sunspot number. Also the indices used, eg, sunspot number and ( $\left.\mathrm{Aa}^{*}-60\right)$, are not perfect indicators of galactic and solar proton fluence.

As mentioned before, the solar-proton-caused fluctuations of ${ }^{14} \mathrm{C}$ is twice the amplitude of the 11 -yr cycle in ${ }^{14} \mathrm{C}$ due to galactic cosmic rays. This suggests that the average ${ }^{14} \mathrm{C}$ level of the atmosphere was raised by $0.3 \%$ during the 17th and 18th solar cycle. The attenuation of an 11-yr cycle in the Oeschger et al (1975) box diffusion model with a separated stratosphere and troposphere and the Lingenfelter and Ramaty (1970) production function is a factor of 54 . Multiplying the $0.3 \%$ by 54 yields a $16 \%$ contribution by solar protons to the ${ }^{14} \mathrm{C}$ production rate during those cycles. Lingenfelter and Ramaty (1970) calculated a contribution of $14 \%$ at $20 \%$ normal cutoffs for the 19 th solar cycle. They obtained $6 \%$ for normal cutoffs. Our values for the 17th and 18th solar cycles are compatible with Lingenfelter and Ramaty's $(1970, p 527)$ assertion that "geomagnetic storms following major solar flares can reduce the effective cutoff rigidities to as small as $20 \%$ of the normal cutoff rigidities". 


\section{CONCLUSION}

The following conclusions appear to be warranted from our analysis:

1) The spectrum of atmospheric ${ }^{14} \mathrm{C}$ variations consists of a long-term trend that can be fit by a ca 11,000-yr sinusoidal curve with half amplitude $\pm 51 \%$, fine structure including a ca 2300 -yr period with half amplitude $\pm 3.5 \%$ and a ca 200 -yr period with half amplitude that does not exceed $\pm 15 \%$ o during the last seven millennia. There are two components to the hyperfine structure. One is the result of solar-wind modulation of galactic cosmic rays with a half amplitude of ca $\pm 1.5 \%$. The other is the result of solar cosmic rays that arrive more randomly but rise and fall with the 11-yr cycle and appear to dominate the fluctuation in the galactic component by a factor of two.

2) The long-term trend is caused by variation of the earth's geomagnetic dipole moment. The ca 2300 -yr period is of uncertain origin whereas the other fine and hyperfine components are the result of solar modulation. Both the geomagnetic field and the ca 2300 -yr period modulate the solar-induced components of the fine and hyperfine structure.

3) The proton fluence from solar flares is effective in producing ${ }^{14} \mathrm{C}$. Its contribution to atmospheric ${ }^{14} \mathrm{C}$ production during the 17 th and 18 th solar cycle was $16 \%$ of the galactic cosmic-ray-produced ${ }^{14} \mathrm{C}$.

4) Point 3 is compatible with a reduction of the effective cutoff rigidity to $20 \%$ of the normal cutoff rigidity during intense solar flare activity as suggested by Lingenfelter and Ramaty (1970).

5) Further refinement of the analysis of solar-flare-produced ${ }^{14} \mathrm{C}$ requires ${ }^{14} \mathrm{C}$ analysis of more recent tree rings that record ${ }^{14} \mathrm{C}$ levels during a time when more information is available.

6) The record of solar-flare-produced ${ }^{14} \mathrm{C}$ in tree rings provides the opportunity to search for unusually intense solar proton fluences during the last nine millennia.

The existence of the large secular variation of atmospheric ${ }^{14} \mathrm{C}$, shown in Figure 1, had been established by the time of the 12th Nobel Symposium in August 1969 (Olsson, 1970). The de Vries Effect fine structure due to solar activity had also been established, as well as Lingenfelter and Ramaty's theoretical basis for the hyperfine structure resulting from the 11-yr cycle in the galactic cosmic-ray flux and solar-proton-related production of ${ }^{14} \mathrm{C}$. Emulation of the high standards of precision and accuracy established by $G$ W Pearson at Belfast University and $M$ Stuiver at the University of Washington has made it possible to verify Lingenfelter and Ramaty's prediction of the role of solar protons. We now have the opportunity of extending the meager $50-y r$ record of these events back through the Holocene. The precise data for calibrating the ${ }^{14} \mathrm{C}$ time scale make it possible also to define fine structure in the variation of the earth's dipole moment. We never cease to be amazed at the wealth of information contained within the carbon isotope record in tree rings.

\section{ACKNOWLEDGMENTS}

Thomas Harlan of the Laboratory of Tree Ring Research provided the annual rings from the Radio Ridge tree. Carlos Ratto and Janet Schaller 
assisted in laboratory work. Joe Allen of the World Data Center-NOAA made available the $\mathrm{Aa}^{*}$ data. We benefited from helpful conversations with Joe Allen, Joan Feynman, Devendra Lal, Richard Lingenfelter and Austin Long. This work was funded by NSF Grant ATM-8607161 and the State of Arizona.

\section{REFERENCES}

Beer, J, Siegenthaler, U, Bonani, G, Finkel, RC, Oeschger, H, Suter, M and Wölfli, W, 1988, Information on past solar activity and geomagnetism from ${ }^{10} \mathrm{Be}$ in the Camp Century ice core: Nature, v 331, p 675-679.

Bruns, M, Rhein, M, Linick, TW and Suess, HE, 1983, The atmospheric ${ }^{14} \mathrm{C}$ level in the 7 th millennium BC, in Mook, WG and Waterbolk, HT, eds, ${ }^{14} \mathrm{C}$ and Archaeology: Strasbourg, PACT, v 8, p 511-516.

Cain, WF, $1979,{ }^{14} \mathrm{C}$ in modern American trees, in Berger, $\mathrm{R}$ and Suess, HE, eds, Radiocarbon dating, Internatl ${ }^{14} \mathrm{C}$ conf, 9th, Proc: Berkeley, Univ California Press, p 495-510.

Castagnoli, G and Lal, D, 1980, Solar modulation effects in terrestrial production of carbon-14, in Stuiver, $\mathrm{M}$ and $\mathrm{Kra}, \mathrm{RS}$, eds, Internatl ${ }^{14} \mathrm{C}$ conf, 10th, Proc: Radiocarbon, v 22, no. 2, $\mathrm{p}$ 133-158.

Clark, RM, 1975, A calibration curve for radiocarbon dates: Antiquity, v 49, p 251-266.

Cook, ER and Holmes, RL, (ms) 1985, Users manual for program ARSTAN: available from ER Cook, Lamont-Doherty Geological Observatory, Palisades, NY or RL Holmes, Laboratory of Tree Ring Research, Univ Arizona, Tucson.

Damon, PE, 1970, Climatic versus magnetic perturbation of the atmospheric ${ }^{14} \mathrm{C}$ reservoir, in Olsson, IU, ed, Radiocarbon variations and absolute chronology, Nobel symposium, 12th, Proc: New York, John Wiley \& Sons, p 571-593.

Damon, PE and Linick, TW, 1986, Geomagnetic-heliomagnetic modulation of atmospheric radiocarbon production, in Stuiver, $\mathrm{M}$ and $\mathrm{Kra}, \mathrm{RS}$, eds, Internatl ${ }^{14} \mathrm{C}$ conf, $12 \mathrm{th}$, Proc: Radiocarbon, v 28 , no. $2 \mathrm{~A}$, p 266-278.

Damon, PE and Sonett, CP, 1989, Solar and terrestrial components of the atmospheric ${ }^{14} \mathrm{C}$ variation spectrum, in Sonett, CP, ed, The sun in time: Tucson, Univ Arizona Press (in press).

Damon, PE, Sternberg, RS and Radnell, CJ, 1983, Modeling of atmospheric radiocarbon fluctuations for the past three centuries, in Stuiver, M and $\mathrm{Kra}$, RS, eds, Internatl ${ }^{14} \mathrm{C}$ conf, 11th, Proc: Radiocarbon, v 25, no. 2, p 249-258.

Dansgaard, W, Johnsen, SJ, Clausen, HB and Langway, CC, Jr, 1971, Climatic record revealed by the Camp Century ice core, in Turekian, KK, ed, The Late Cenozoic glacial ages: New Haven, Yale Univ Press, p 37-56.

Eddy, JA, 1976a, The Maunder minimum: Science, v 192, p 1189-1202.

1976b, The sun since the Bronze Age, in Williams, DJ, ed, Physics of solar planetary environments, 2: Washington, DC, Am Geophys Union, p 958-972.

Elsasser, WE, Ney, EP and Winckler, JR, 1956, Cosmic ray intensity and geomagnetism: Nature, v 178, p 1226-1227.

Houtermans, JC, (ms) 1971, Geophysical interpretations of bristlecone pine radiocarbon measurements using a method of Fourier analysis for unequally-spaced data: PhD dissert, Univ Bern, Switzerland.

Kromer, B, Rhein, M, Bruns, M and Schoch-Fischer, H, 1986, Radiocarbon calibration data for the 6th to the 8th millennia BC, in Stuiver, M and Kra, RS, eds, Internatl ${ }^{14} \mathrm{C}$ conf, 12 th, Proc: Radiocarbon, v 28, no. 2B, p 954-960.

Lal, D, 1988, Theoretically expected variations in the terrestrial cosmic-ray production rates of isotopes, in Castagnoli, GC, ed, Solar terrestrial relationships and the earth environment in the last millennia: Bologna, Italian Physical Soc, p 216-233.

Lal, D, Laffoon, MA and Erickson, DJ, III, 1988, in Proceedings of the Lake Arrowhead Conference on interaction of the global carbon and climate systems, Lake Arrowhead, California, Oct 1988 (preprint).

Lal, L and Peters, B, 1967, Cosmic ray produced radioactivity on the earth, in Flügge, S, ed, Encyclopedia of physics, v 46/2: New York, Springer-Verlag.

Lamb, HH, 1965, The early medieval warm epoch and its sequel: Palaeogeog, Palaeoclimatol, Palaeoecol, v 1, p 13-37. 
Lingenfelter, RE and Ramaty, R, 1970, Astrophysical and geophysical variations in C 14 production, in Olsson, IU, ed, Radiocarbon variations and absolute chronology, Nobel symposium, 12th, Proc: New York, John Wiley \& Sons, p 513-537.

Linick, TW, Long, A, Damon, PE and Ferguson, CW, 1986, High-precision radiocarbon dating of bristlecone pine from 6554 to $5350 \mathrm{BC}$, in Stuiver, M and Kra, RS, eds, Internatl ${ }^{14} \mathrm{C}$ conf, 12th, Proc: Radiocarbon, v 28, no. 2B, p 943-953.

Long, A, Arnold, LD, Damon, PE, Ferguson, CW, Lerman, JC and Wilson, AT, 1979, in Berger, $\mathrm{R}$ and Suess, $\mathrm{HE}$, eds, Radiocarbon dating, Internatl ${ }^{14} \mathrm{C}$ conf, 9 th, Proc: Berkeley, Univ California Press, p 495-510.

Lund, SP and Banerjee, SK, 1985, Late Quaternary paleomagnetic field secular variation from two Minnesota lakes: Jour Geophys Research, v 90, no. B1, p 803-825

Mayhaud, PN, 1972, The Aa indices: A 100 year series characterizing the magnetic activity: Jour Geophys Research, v 77, p 6870-6874.

Merrill, RT and McElhinny, MW, 1983, The earth's magnetic field, its history, origin and planetary perspective: London, Academic Press, 401 p.

Oeschger, H, Siegenthaler, U, Schotterer, U and Guelmann, A, 1975, A box diffusion model to study the carbon dioxide exchange in nature: Tellus, v 27, p 168-192.

Olsson, IU, ed, 1970, Radiocarbon variations and absolute chronology, Nobel Symposium, 12th, Proc: New York, John Wiley \& Sons, 652 p.

Pearson, GW, Pilcher, JR, Baillie, MGL, Corbett, DM and Qua, F, 1986, High precision ${ }^{14} \mathrm{C}$ measurement of Irish oaks to show the natural variations from AD 1840-5210 BC, in Stuiver, M and Kra, RS, eds, Internatl ${ }^{14} \mathrm{C}$ conf, 12th, Proc: Radiocarbon, v 28, no. 2B, p 911-934.

Pearson, GW and Stuiver, M, 1986, High precision calibration of the radiocarbon time scale, $500-2500 \mathrm{BC}$, in Stuiver, M and Kra, RS, eds, Internat ${ }^{14} \mathrm{C}$ conf, 12th, Proc: Radiocarbon, v 28, no. 2B, p 839-862.

Schmidt, B and Gruhle, W, 1988, Klima, radiokohlenstoffgehalt und dendrochronologie: Naturw Rundschau, v 5, p 177-182.

Siegenthaler, U, Heimann, M and Oeschger, $\mathrm{H}, 1980,{ }^{14} \mathrm{C}$ variations caused by changes in the global carbon cycle, in Stuiver, $\mathrm{M}$, and $\mathrm{Kra}, \mathrm{RS}$, eds, Internatl ${ }^{14} \mathrm{C}$ conf, 10 th, Proc: Radiocarbon, v 22, no. 2, p 177-191.

Sonett, CP, 1984, Very long solar periods and the radiocarbon record: Rev Geophysics Space Physics, v 22, no. 3, p 239-254.

Sternberg, RS and Damon, PE, 1979, Sensitivity of radiocarbon fluctuations and inventory to geomagnetic parameters, in Berger, $\mathrm{R}$ and Suess, HE, eds, Radiocarbon dating, Internatl ${ }^{14} \mathrm{C}$ conf, 9th, Proc: Berkeley, Univ California Press, p 691-720.

Stuiver, $\mathrm{M}$ and Kra, RS, eds, 1986, Calibration issue, Internat ${ }^{14} \mathrm{C}$ conf, 12 th, Proc: Radiocarbon, v 28, no. 2B, p 805-1030.

Stuiver, $\mathrm{M}$ and Pearson GW, 1986, High precision calibration of the radiocarbon time scale, AD 1950-500 C, in Stuiver, M and Kra, RS, eds, Internatl ${ }^{14} \mathrm{C}$ conf, 12th, Proc: Radiocarbon, v 28, no. 2B, p 805-838.

Stuiver, M, Pearson, GW and Braziunas, T, 1986, Radiocarbon age calibration of marine samples back to $900 \mathrm{cal}$ yr BP, in Stuiver, $\mathrm{M}$ and Kra, RS, eds, Internat ${ }^{14} \mathrm{C}$ conf, 12th, Proc: Radiocarbon, v 28, no. 2B, p 980-1021.

Stuiver, $\mathrm{M}$ and Quay, PD, 1980, Changes in atmospheric ${ }^{14} \mathrm{C}$ attributed to a variable sun: Science, $v$ 9, $\mathrm{p} 1-20$

1981, Atmospheric ${ }^{14} \mathrm{C}$ changes resulting from fossil fuel $\mathrm{CO}_{2}$ release and cosmic ray flux variability: Earth Planetary Sci Letters, v 53, p 349-362.

Suess, HE, 1980, The radiocarbon record in tree rings of the last 8000 years, in Stuiver, $M$ and Kra, RS, eds, Internatl ${ }^{14} \mathrm{C}$ conf, 10th, Proc: Radiocarbon, v 22, no. 2, p 200-209. 